\title{
Iron Oxide Mediated Degradation of Mutagen Pyrene and Determination of Degradation Products
}

\author{
Bina Gupta and Himanshu Gupta
}

\begin{abstract}
Photocatalytic degradation of pyrene, a potent mutagen, has been studied on synthesized iron oxide, goethite and on soil surfaces in presence of goethite. The effect of soil pH and UV irradiation wavelength was also investigated. The decay profiles in all the cases follow first order kinetics. The results reveal that photodegradation of pyrene in soil is maximum under UV irradiation of short wavelength. The rate constants for the degradation of pyrene in the presence of optimum photocatalytic dose of goethite were $1.03 \times 10^{-2}, 3.52 \times$ $10^{-3}$ and $8.99 \times 10^{-3} \mathrm{~h}^{-1}$, for acidic, neutral and alkaline soils respectively. Samples were analysed using high performance liquid chromatography in an isocratic mode and degradation products were identified using liquid chromatography-mass spectrometry. Present work clearly demonstrates that goethite effectively disintegrates pyrene in soil into smaller non-toxic fragments.
\end{abstract}

Index Terms-HPLC-MS, iron oxides, metabolites, pyrene.

\section{INTRODUCTION}

Polycyclic aromatic hydrocarbons (PAHs), present ubiquitously in the environment, are pollutants of concern because of their toxic, mutagenic and carcinogenic potential. Natural activities like eruption of volcanoes, forest fires as well as anthropogenic activities like domestic wood burning, cigarette smoke, vehicular traffic exhausts and industrial releases are responsible for the entry of the PAHs in the environment. The USEPA has considered 16 PAHs as harmful pollutants based on their toxicity and exposure to humans. Increased industrialisation, transportation, spillage and improper disposal of crude oils have resulted in PAH contaminated sites around the world [1]-[4] posing ecological and health risks. This necessitates the need to understand the fate of PAHs in the environment. Pyrene, a four ringed PAH is frequently used as a model PAH. Pyrene is a dominant mutagen found in PAH contaminated soils [5], [6]. Despite of not being a carcinogen, it enhances the carcinogenic effects of benzo[a]pyrene [7]. Thus pyrene was selected for the present studies.

Microbial [7]-[10] and photocatalytic [11]-[14] degradation of PAHs has been studied by various researchers. Limitation with microbial degradation is that the rate of degradation is slow for high molecular weight (more than three ring) PAHs [15]. Both $\mathrm{TiO}_{2}$ and iron oxides have been used as photocatalyst for the degradation of PAHs. Iron oxides in comparison to $\mathrm{TiO}_{2}$ are cheap and easily synthesized in the laboratory. Moreover, the

Manuscript received September 29, 2014; revised March 12, 2015. This work was supported by the Ministry of Human Resources and Development, India.

Bina Gupta and Himanshu Gupta are with the Indian Institute of Technology Roorkee, Roorkee-247667, Uttarakhand, India (e-mail: dr.binagupta@gmail.com). degradation rates achieved with both type of photocatalysts are comparable [16], [17]. Photodegradation of pyrene on soil surfaces in presence of $\mathrm{TiO}_{2}$ [16] and haematite [17] has been studied. Another iron oxide, goethite, has also been used for the photodegradation of pyrene by Wang et al. [18]. The authors used solid catalyst surface for the degradation studies and reported pyreno as an intermediate product of photodegradation of pyrene. No other attempts have been made to identify the metabolites of photodegradation of pyrene. In view of this, degradation of mutagenic PAH pyrene was planned in presence of goethite, an iron oxide, in soil under a set of optimised conditions. The effect of various parameters like irradiation wavelength, soil $\mathrm{pH}$ and amount of iron oxide on the degradation was studied and degradation products were identified.

\section{MATERIALS AND METHODS}

\section{A. Chemicals}

Pyrene (>99\%) was purchased as certified standard from HIMEDIA. HPLC grade Acetonitrile (ACN), ferric nitrate nonahydrate, potassium hydroxide and fluorisil were supplied by RANKEM. Ultrapure water was used throughout the analysis. Three different soil samples collected from different regions of India - Uttarkashi (Uttarakhand), Roorkee (Uttarakhand) and Sriganganagar (Rajasthan), were sieved to less than 75 micrometer and sterilised twice in an autoclave at $121^{\circ} \mathrm{C}$ for $30 \mathrm{~min}$. A stock solution of pyrene was prepared with a concentration of $1000 \mu \mathrm{g} \mathrm{mL}{ }^{-1}$ in $\mathrm{ACN}$ and stored in dark at $4{ }^{\circ} \mathrm{C}$.

\section{B. HPLC and LC-MS}

Samples of the degradation studies were analysed using Agilent 1100 series HPLC (Agilent Technologies, USA) equipped with UV detector and an Octadecyl end capped $\mathrm{RP}_{-} \mathrm{C}_{18}$ column $(250 \times 4.6 \mathrm{~mm}, 5 \mu \mathrm{m})$. A binary solvent system comprising of acetonitrile:water (90:10) in an isocratic mode was used as an eluent at a flow rate of $1 \mathrm{~mL}$ $\min ^{-1}$. Twenty microliter sample was injected for each analysis. Pyrene was eluted at a retention time of $5.8 \mathrm{~min}$ under above mentioned conditions. A linear calibration plot was obtained in the concentration range 0.2 to $100 \mu \mathrm{g} \mathrm{mL}^{-1}$. Metabolites were identified using LC-MS (Shimadzu Corporation, Kyoto, Japan) with Labsolutions software version. The instrument is equipped with automatic injection, a binary pump and UV-Vis detector coupled in series with a mass selective detector equipped with an electron spray ionization source. An Octadecyl end capped RP- $\mathrm{C}_{18}$ column $(100 \times 1.6 \mathrm{~mm})$ and a binary solvent system consisting of acetonitrile: water (70:30) with a flow rate of $0.2 \mathrm{~mL} / \mathrm{min}$ were employed for the analysis. Ionization of analytes was carried out using the following conditions in 
ESI mode: nebulizer gas flow 10 psi, dry gas $10 \mathrm{Lmin}^{-1}$, dry temperature $250{ }^{\circ} \mathrm{C}$, capillary voltage $4000 \mathrm{~V}$, fragmentor voltage $100 \mathrm{~V}$, vaporiser temperature $250^{\circ} \mathrm{C}$.

\section{Synthesis and Characterisation of Goethite}

Goethite was synthesized using precipitation method [19] involving addition of potassium hydroxide to ferric nitrate solution dropwise with constant and rapid stirring to make the solution highly alkaline. A red brown precipitate obtained was diluted with deionised water and kept in an oven for $72 \mathrm{~h}$ at $70-75^{\circ} \mathrm{C}$. Goethite was obtained as a light yellow coloured precipitate which was washed with double distilled water and dried in an oven at $50-55{ }^{\circ} \mathrm{C}$. Goethite was characterised by powder X-ray diffraction (XRD) using Bruker AXS D8 powder diffractometer employing $\mathrm{Cu} K_{\alpha}$ radiation $\left(40 \mathrm{kV}, 45 \mathrm{~mA}, \lambda=1.5418 \mathrm{~A}^{\circ}\right)$ and goniometer speed of $2 \% \mathrm{~min}$.

\section{Photodegradation Experiments}

Pyrene was photodegraded in a UV cabinet and irradiated with a selected wavelength of $254 \mathrm{~nm}$ unless mentioned otherwise. All the analysis was carried out in three replicates. Soil samples $(1 \mathrm{~g})$ containing pyrene $(50 \mu \mathrm{g})$ were mixed with a definite amount of goethite and irradiated in the UV chamber for $0-120 \mathrm{~h}$. To study the effect of different variables investigations were carried out at varying irradiation wavelength, photocatalytic dose and soil $\mathrm{pH}$. The samples were removed periodically at a regular interval of 24 h. Soil samples removed were extracted through developed method and analysed using HPLC and LC-MS.

\section{E. Extraction of Pyrene from Soil}

Soil samples were extracted with $5 \mathrm{~mL}$ ACN in an ultrasonic bath at $20-25^{\circ} \mathrm{C}$ for $40-45 \mathrm{~min}$. The extract was centrifuged at $3000 \mathrm{rpm}$ for $10 \mathrm{~min}$. A thin layer of anhydrous sodium sulphate followed by $1 \mathrm{~g}$ of florisil was introduced in a column in order to perform in situ clean up. The final extracts were passed through the column, rinsed with $\mathrm{ACN}(8 \mathrm{~mL})$ and concentrated to the appropriate volume using rotary evaporator and analysed through HPLC. The percentage recovery of pyrene from soil in all the cases was found to be $>95 \%$.

\section{RESULTS AND DISCUSSION}

\section{A. Characterisation of Goethite}

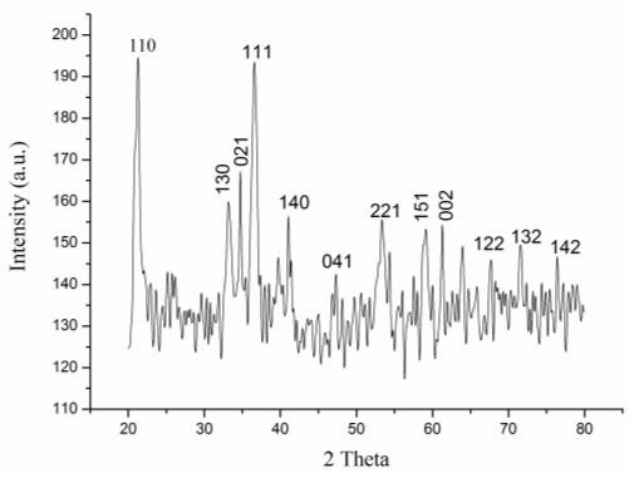

Fig. 1. XRD spectrum of iron oxide goethite.

XRD spectrum of synthesized iron oxide goethite is shown in Fig. 1. XRD data was concordant to the JCPDSICDD (1979). The crystallite size $(9.83 \mathrm{~nm})$ was calculated using Scherrer's equation i.e. $D=(0.9 \lambda) /(\beta \cos \theta)$, where $\lambda$ is $\mathrm{X}$-ray wavelength, $\beta$ is line broadening measured at halfheight for the most intense peaks of XRD and $\theta$ is Bragg angle of the particles.

\section{B. Effect of Photocatalyst Dose}

The effect of photocatalyst $(\alpha-\mathrm{FeOOH})$ dose on the photodegradation of pyrene was investigated at $\mathrm{pH} 6.8$ by mixing varying amounts (1-5 wt\%) of goethite to the soil spiked with pyrene. Plots drawn between natural log of pyrene concentration and time gave straight line, suggesting first order rate kinetics (Fig. 2). The first order rate constant values are $1.24 \times 10^{-3}, 3.05 \times 10^{-3}, 3.18 \times 10^{-3}, 3.52 \times 10^{-3}$, $3.36 \times 10^{-3}$ and $3.34 \times 10^{-3} \mathrm{~h}^{-1}$ corresponding to catalyst dose of $0,1,2,3,4$ and $5 \mathrm{wt} \%$, respectively. Results further reveal that the photodegradation of pyrene is significantly higher in the presence of photocatalyst goethite and increase in the amount of catalyst further enhances the rate of disintegration of pyrene upto $3 \mathrm{wt} \%$ of goethite. The results indicated that the degradation of pyrene in presence of 3 wt $\%$ of goethite $\left(k=3.52 \times 10^{-3} \mathrm{~h}^{-1}\right)$ is slightly higher than the degradation of pyrene in presence of $3 \mathrm{wt} \%$ haematite $(k$ $\left.=3.4 \times 10^{-3} \mathrm{~h}^{-1}\right)$ reported by Zhang et al. [17].

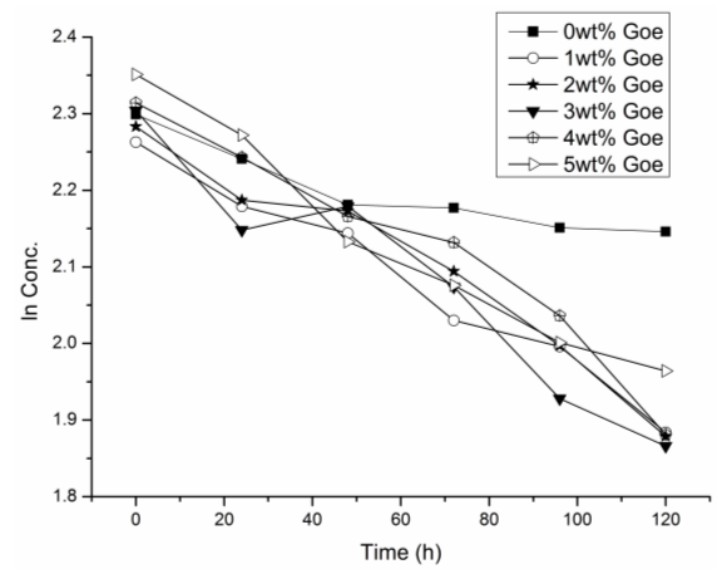

Fig. 2. Effect of dose of $\alpha-\mathrm{FeOOH}$ on photodegradation of pyrene at $\mathrm{pH} 6.8$.

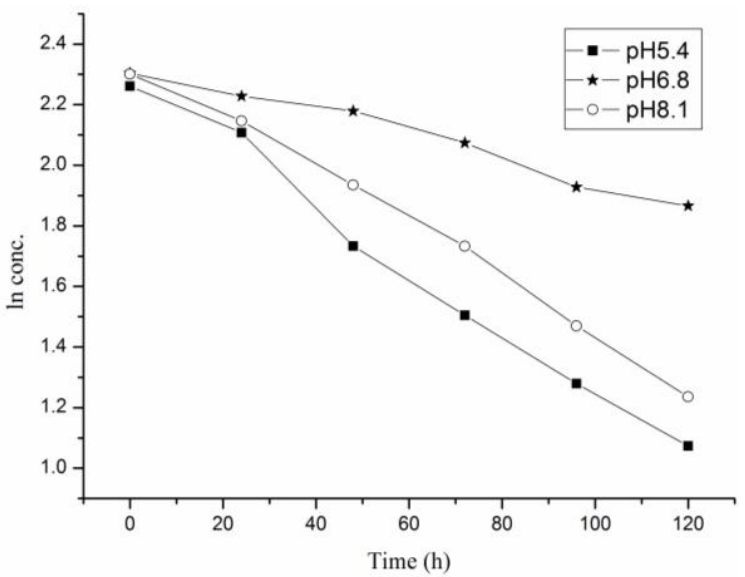

Fig. 3. Effect of soil $\mathrm{pH}$ on photocatalytic degradation of pyrene.

\section{Effect of Soil $p H$}

To examine the effect of soil $\mathrm{pH}$, photodegradation of pyrene was carried out in the soils of varying $\mathrm{pH}(5.4,6.8$ and 8.1). At all the three $\mathrm{pH}$, concentration of pyrene 
decreases exponentially with time, suggesting first order rate kinetics (Fig. 3). The values of rate constant corresponding

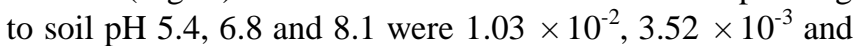
$8.99 \times 10^{-3} \mathrm{~h}^{-1}$, respectively. It is evident from the results that the rate of degradation of pyrene is faster in acidic and alkaline soils than neutral soil. Zhang and coworkers [16] also reported faster degradation of pyrene in acidic and alkaline soils in presence of photocatalyst $\mathrm{TiO}_{2}$.

\section{Effect of $U V$ Wavelength}

The disintegration of pyrene was examined under three different wavelengths i.e. 254,365 and $410 \mathrm{~nm}$. The values of rate constants are $3.52 \times 10^{-3}, 3.10 \times 10^{-3}$ and $2.01 \times 10^{-3}$ $\mathrm{h}^{-1}$ at wavelengths 254,365 , and $410 \mathrm{~nm}$, respectively. The results suggest that the degradation of pyrene decreases with the increase in irradiation wavelength. Faster degradation at shorter wavelength can be explained on the basis of the fact that the lower is the wavelength, higher is the energy of the incident radiation.

\section{E. Degradation Products}

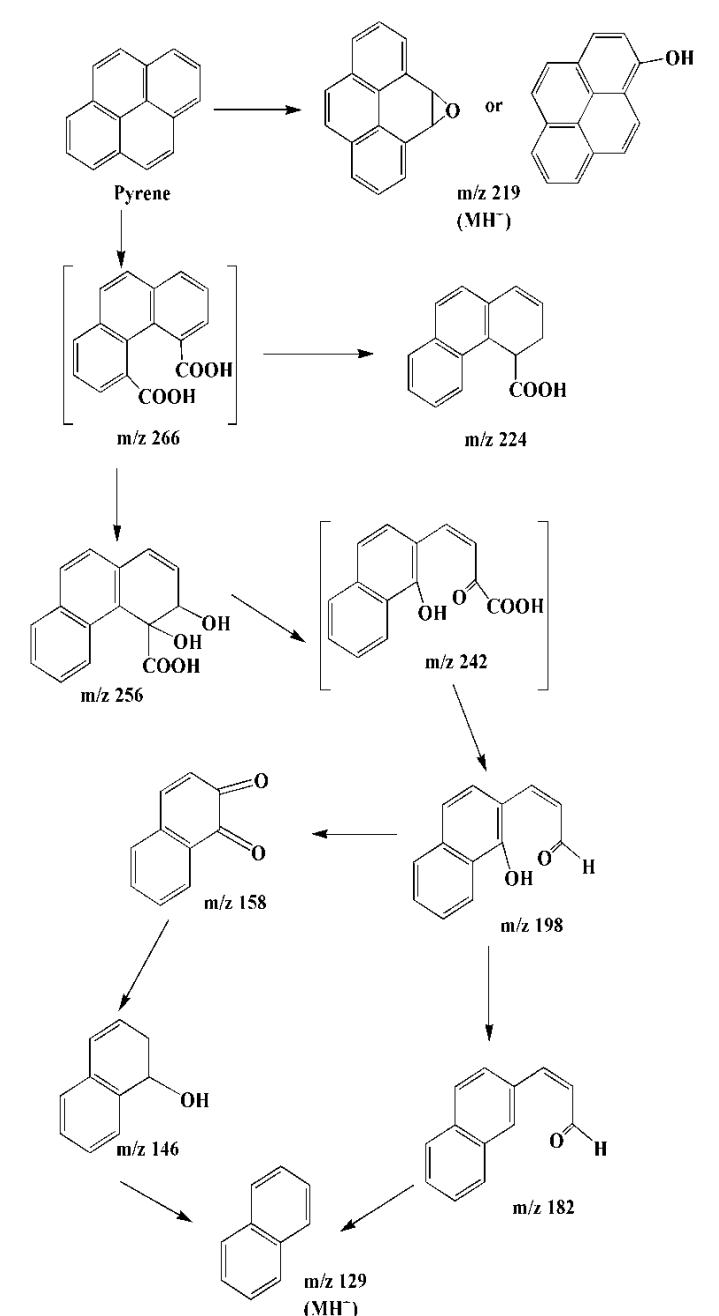

Fig. 4. Possible pathway for the degradation of pyrene in neutral soil. Structures in brackets are hypothetical intermediates.

Pyrene was degraded photochemically in acidic, neutral and alkaline soils under optimised conditions (3 wt \% goethite, $254 \mathrm{~nm}$ wavelength) for $120 \mathrm{~h}$. The samples were removed, extracted at regular time intervals $(0,24,48,72$, 96 and $120 \mathrm{~h}$ ) and analysed through LC-MS for the identification of different degradation products. The degradation products and their possible pathways in neutral (pH 6.8), basic (pH 8.1) and acidic ( $\mathrm{pH} \mathrm{5.4)} \mathrm{soils} \mathrm{are} \mathrm{shown}$ in Fig. 4-Fig. 6, respectively. In all the three cases, unirradiated samples (zero h) gave a prominent peak of pyrene (parent compound) only.

\section{F. Neutral Soil}

In the beginning (zero h) only the molecular ion peak was observed. Two metabolite peaks at m/z 219 and 100 were observed in addition to the molecular ion peak after $24 \mathrm{~h}$. The metabolite at $\mathrm{m} / \mathrm{z} 219$ is due to 1-hydroxypyrene or pyrene-4,5-epoxide and the peak at $\mathrm{m} / \mathrm{z} 100$ is due to degradation of pyrene to a simpler compound which could not be identified. After $48 \mathrm{~h}$ additional peaks at m/z 224 and 256 were observed which are assigned to 3,4dihydrophenanthrene-4-carboxylic acid and 3,4-dihydroxy3,4-dihydrophenanthrene-4-carboxylic acid. After $72 \mathrm{~h}$, peaks at $\mathrm{m} / \mathrm{z} 224$ and 256 disappeared and new peaks at $\mathrm{m} / \mathrm{z}$ 105 and 198 appeared. The molecular ion peak at m/z 105 could not be identified and the peak at $\mathrm{m} / \mathrm{z} 198$ was assigned to 3-(1-hydroxy-2-naphthalenyl)-2-propenal. After $96 \mathrm{~h}$, the metabolite peaks were observed at $\mathrm{m} / \mathrm{z} 105,182$ and 158 . The metabolite peaks at $\mathrm{m} / \mathrm{z} 182$ and 158 have been assigned to 3-(2-naphthalenyl)-2-propenal and 1,2naphthalenedione, respectively. After $120 \mathrm{~h}$, peaks at $\mathrm{m} / \mathrm{z}$ 146, 129 and 158 persist which are due to 1,2dihydronaphthalene-1-ol, naphthalene and 1,2naphthalenedione, respectively.
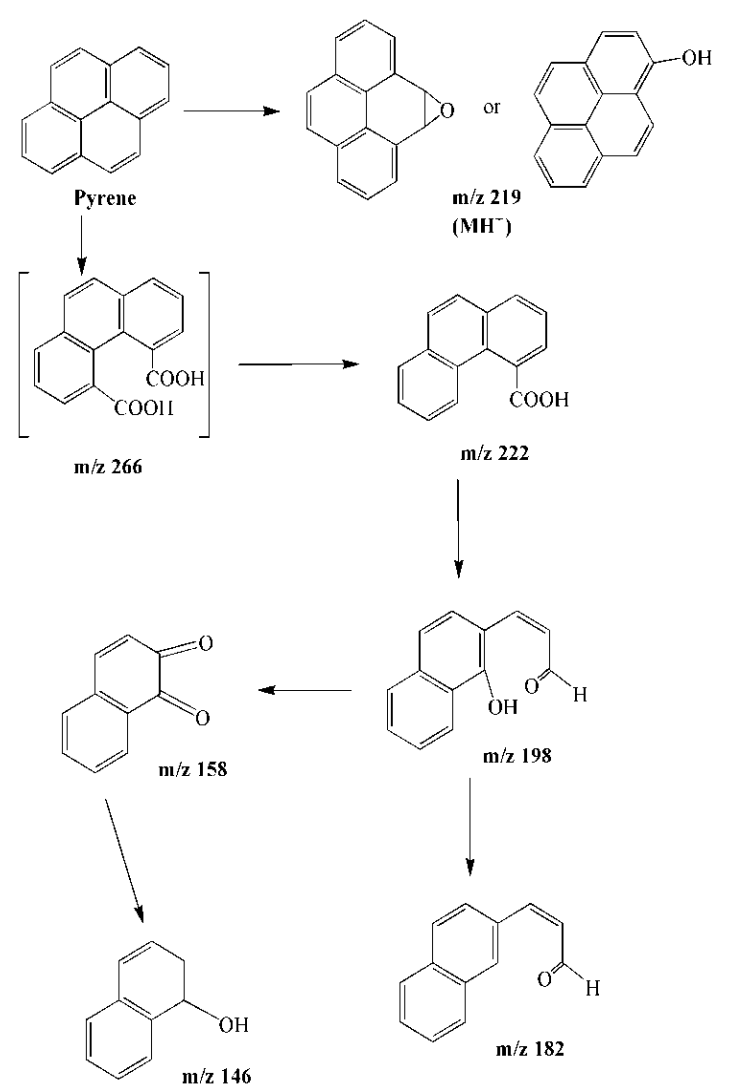

Fig. 5. Possible pathway for the degradation of pyrene in basic soil. Structures in brackets are hypothetical intermediates.

\section{G. Basic Soil}

A metabolite peak at $\mathrm{m} / \mathrm{z} 100$ was observed in addition to the parent ion peak after $24 \mathrm{~h}$. After $48 \mathrm{~h}$, additional peaks at m/z 219 and 198 were observed. After 72 h, the metabolite 
peaks observed were at $\mathrm{m} / \mathrm{z} 100,105,222,219$ and 158 . The metabolite peaks at $\mathrm{m} / \mathrm{z} 222$ was assigned to phenenanthrene-4-carboxylic acid. Metabolite peaks at $\mathrm{m} / \mathrm{z}$ 105, 182 and 158 were observed after $96 \mathrm{~h}$. After $120 \mathrm{~h}$, only the metabolites with $\mathrm{m} / \mathrm{z} 100$ and 146 were discernible.

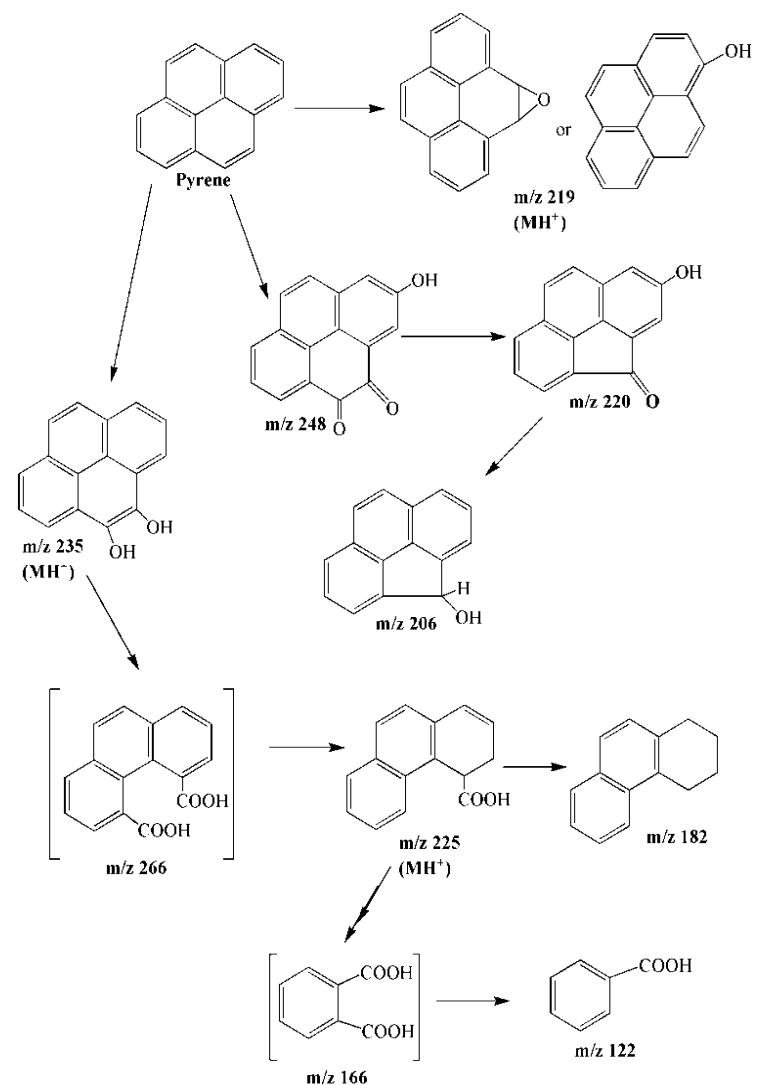

Fig. 6. Possible pathway for the degradation of pyrene in acidic soil. Structures in brackets are hypothetical intermediates.

\section{H. Acidic Soil}

After $24 \mathrm{~h}$, two metabolite peaks were observed at $\mathrm{m} / \mathrm{z}$ 105 and 219, in addition to the parent ion peak. After $48 \mathrm{~h}$, new metabolite peaks at $\mathrm{m} / \mathrm{z} 248$ and 220 appeared which were assigned to 2-hydroxypyrene-4,5-dione and 6hydroxy-4H-cyclopenta[def]phenanthrene-4-one, respectively.

After 72 h, the metabolites with m/z 219, 248 and 220 disappeared and new peaks at m/z 235, 225 and 206 appeared which were assigned to 4,5-dihydroxypyrene, phenanthrene-4-carboxylic acid and 4Hcyclopenta[def]phenanthrene-4-ol, respectively. After $96 \mathrm{~h}$, the detected peaks were at $\mathrm{m} / \mathrm{z} 100,105,182,225$ and 122. The metabolite peak at $\mathrm{m} / \mathrm{z} 122$ was assigned to benzoic acid. Only the metabolite peaks at $\mathrm{m} / \mathrm{z} 100$ and 182 were found persistent after $120 \mathrm{~h}$.

On the basis of the observed metabolites, it can be concluded that the degradation of pyrene occurs through oxidative mechanism. A typical total ion chromatogram and corresponding full scan mass spectrum of pyrene are shown in Fig. 7(a) and 7(b), respectively. Blank experiments for the photodegradation of pyrene in soil in the absence of catalyst were conducted for $0,24,48,72,96$ and $120 \mathrm{~h}$. A prominent peak due to pyrene was observed in all the samples and only a few of the identified metabolite peaks (m/z 224, 182, 105 and 102) were detected till $120 \mathrm{~h}$, which indicates that the degradation of pyrene is slow in the absence of the catalyst and may involve mechanism similar to the degradation occurring in presence of the catalyst. The degradation products may also appear in the form of other possible isomers, in addition to the metabolites shown in the degradation pathways. In different soils, the nature and persistence of the degradation products are different due to dissimilar chemical environment. In neutral and basic soils, the metabolites follow the similar pathway for the photodegradation of pyrene, while in acidic soil, the different metabolic pathway is followed. The metabolites were confirmed by selective ion monitoring (SIM) and product ion scan. The metabolite peaks were detected at $[\mathrm{M}]^{+}$or $[\mathrm{M}+\mathrm{H}]^{+}$. Several identified metabolites have been reported earlier under different experimental conditions [7], [8], [20]-[23]. Metabolites with m/z 158, 146, 129 and m/z 100, 146 (naphthalene and its derivatives) were found to be persistent in basic and neutral soil, respectively after $120 \mathrm{~h}$. In case of acidic soil, metabolites with m/z 100 and 182 (hydrogenated phenanthrene) were found persistent after $120 \mathrm{~h}$. The degradation pathways indicated that the mutagen pyrene is degraded efficiently in presence of goethite into smaller non-carcinogenic/non-mutagenic hydrocarbons (naphthalene, phenanthrene and their derivatives) after 120 h.
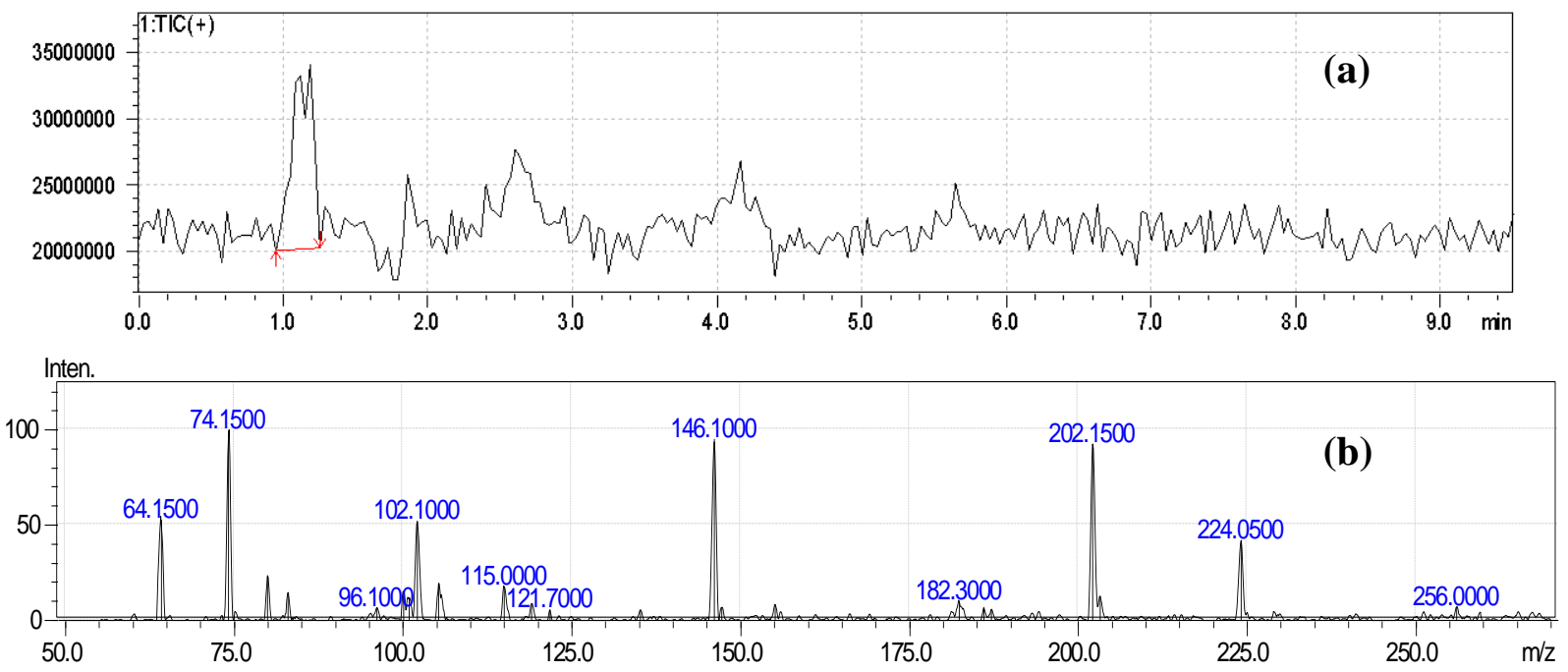

Fig. 7. Total ion chromatogram (a) and full scan mass spectrum (b) of metabolites of pyrene in soil (pH 6.8) after $48 \mathrm{~h}$. 


\section{CONCLUSIONS}

Present study reports an inexpensive and efficient approach for the photodegradation of pyrene in the soils of varying $\mathrm{pH}$ involving goethite as a photocatalyst. The decay in all the cases follow first order kinetics. The effect of soil $\mathrm{pH}$, wavelength and catalyst dose on the photodegradation suggest fast and efficient degradation of pyrene in presence of $3 \mathrm{wt} \%$ goethite. The results further indicate that the photodegradation of pyrene is faster in acidic and alkaline soils than neutral soils. The results reveal that the photodegradation of pyrene occurs through oxidative metabolism. The study provides an efficient method for the remediation of pyrene contaminated soil surfaces where pyrene is degraded to smaller hydrocarbons, naphthalene, phenanthrene and their derivatives. The present work will also provide metabolite data bank for other toxicological studies.

\section{REFERENCES}

[1] T. Agrawal, "Concentration, level, pattern and toxic potential of PAHs in traffic soils of Delhi, India," J. Hazard. Mater., vol. 171, pp. 894900, June 2009.

[2] W. Yang, Y. Lang, and G. Li, "Cancer risk of polycyclic aromatic hydrocarbons (PAHs) in the soils from Jiaozhou Bay wetland,' Chemosphere, vol. 112, pp. 289-295, May 2014.

[3] S. S. Sojinu, J. Z. Wang, O. O. Sanibare, and E. Y. Zeng, "Polycyclic aromatic hydrocarbons in sediments and soils from oil exploration areas of the Niger Delta, Nigeria," J. Hazard. Mater., vol. 174, pp. 641647, Sept. 2009.

[4] N. B. Sam, Y. Ikenaka, S. M. M. Nakayama, O. Akoto, Y. B Yohannes, E. Baidoo, H. Mizukawa, and M. Ishizuka, "Occurrence, distribution, sources and toxic potential of polycyclic aromatic hydrocarbons (PAHs) in surface soils from the Kumasi Metropolis, Ghana," Sci. Tot. Environ., vol. 496, pp. 471-478, Aug. 2014.

[5] C. E. Cerniglia, "Biodegradation of polycyclic aromatic hydrocarbons," Biodegradation., vol. 3, pp. 351-368, 1992

[6] K. Jayasimhulu, W. Xue, D. Warshawsky et al., "Degradation of pyrene, benz[a]anthracene, and benzo[a]pyrene by mycobacterium sp. strain RJGII-135, isolated from a former coal gasification site," Appl. Environ. Microbiol., vol. 62, no. 1, pp. 13-19, Jan. 1996.

[7] S. J. Kim, O. Kweon, R. C. Jones, J. P. Freeman, R. D. Edmondson and C. E. Cerniglia, "Complete and integrated pyrene degradation pathway in mycobacterium vanbaalenii PYR-1 based on systems biology," J. Bacteriology, vol. 189, no. 2, pp. 464-472, Jan. 2007.

[8] C. Kazunga and M. D. Aitken, "Products from the incomplete metabolism of pyrene by polycyclic aromatic hydrocarbon-degrading bacteria," Appl. Environ. Microbiol., vol. 66, no. 5, pp. 1917-1922, May 2000.

[9] Y. Zhang, F. Wang, C. Wang, Q. Hong, F. O. Kengara, T. Wang, Y. Song, and X. Jiang, "Enhanced microbial degradation of humin-bound phenanthrene in a two-liquid-phase system," J. Hazard. Mater., vol. 186, pp. 1830-1836, Dec. 2010.

[10] M. Wu, L. Chen, Y. Tian, Y. Ding, and W. A. Dick, "Degradation of polycyclic aromatic hydrocarbons by microbial consortia enriched from three soils using two different culture media," Environ. Poll., vol. 178, pp. 152-158, March 2013.

[11] F. Karam, F. H. Hussein, S. J. Baqir, A. F. Halbus, R. dillert, and D. Bahnemann, "Photocatalytic degradation of anthracene in closed system reactor," Int. J. Photoenergy, vol. 2014, p. 6, April 2014.

[12] Y. Guo, J. Gao, M. Yang, Z. Zou et al., "Photocatalytic degradation of polycyclic aromatic hydrocarbons in $\mathrm{GaN}: \mathrm{ZnO}$ solid solution-assisted process: Direct hole oxidation mechanism," J. Mol. Catal. A, vol. 325, pp. 48-54, March 2010.

[13] D. Dong, P. Li, X. Li, C. Xu, D. Gong, Y. Zhang, Q. Zhao, and P. Li, "Photocatalytic degradation of phenanthrene and pyrene on soil surfaces in the presence of nanometer rutile $\mathrm{TiO}_{2}$ under UVirradiation," Chem. Eng. J., vol. 158, pp. 378-383, 2010.

[14] D. Dong, P. Li, X. Li, Q. Zhao, Y. Zhang, C. Jia, and P. Li, "Investigation on the photocatalytic degradation of pyrene on soil surfaces using nanometer anatase $\mathrm{TiO}_{2}$ under UV irradiation," $J$. Hazard. Mater., vol. 174, pp. 859-863, 2010.

[15] P. Henner, M. Schiavon, J. L. Morel, and E. Lichtfouse, "Polycyclic aromatic hydrocarbons (PAH) occurrence and remediation methods," Analusis Magzine, vol. 25, pp. M56-M59, 1997.

[16] Z. Gong, X. Li et al., "Photocatalytic degradation of polycyclic aromatic hydrocarbons on soil surfaces using $\mathrm{TiO}_{2}$ under UV light," $J$. Hazard. Mater., vol. 158, pp. 478-484, Jan. 2008.

[17] N. Jia, C. Xu, X. Li et al., "Photocatalytic degradation of polycyclic aromatic hydrocarbons on soil surfaces using $\mathrm{Fe}_{2} \mathrm{O}_{3}$ under UV light," Advanced Materials Research, vol. 189-193, pp. 420-423, Feb. 2011.

[18] Y. Wang, C. S. Liu, F. B. Li, C. P. Liu, and J. B. Liang, "Photodegradation of polycyclic aromatic hydrocarbon pyrene by iron oxide in solid phase," J. Hazard. Mater., vol. 162, pp. 716-723, 2009.

[19] R. M. Cornell and U. Schwertmann, The Iron Oxides: Structure, Properties, Reactions, Occurrences and Uses, 2nd ed. VCH, Weinheim: Wiley, 2003, ch. 20, p. 531

[20] A. S. Oliveira, L. F. V. Ferreira, J. P. D. Silva, and J. C. Moreira, "Surface photochemistry: Photodegradation study of pyrene adsorbed onto microcrystalline cellulose and silica," Int. J. Photoenergy, vol. 6 , pp. 205-213, 2004.

[21] D. D. Ross and C. E. Cerniglia, "Degradation of pyrene by Mycobacterium flavescens," Appl. Microbiol. Biotechnol., vol. 46. pp. 307-312, April 1996

[22] Y. Liang, D. R. Gardner, C. D. Miller, D. Chen, A. J. Anderson, B. C. Weimer, and R. C. Sims, "Study of biochemical pathways and enzymes involved in pyrene degradation by mycobacterium sp. strain KMS," Appl. Environ. Microbiol., vol. 72, no. 12, pp. 7821-7828, Dec. 2006.

[23] J. Vila, Z. Lopez, J. Sabate, C. Minguillion, A. M. Solanas, and M. Rifoll, "Identification of a novel metabolite in the degradation of pyrene by mycobacterium sp. strain AP1: Actions of the isolate on twoand three-ring polycyclic aromatic hydrocarbons," Appl. Environ. Microbiol., vol. 67, no. 12. pp. 5497-5505, Dec. 2001.

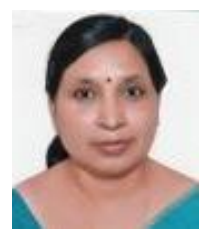

Bina Gupta is working in environmental and analytical chemistry for more than 20 years. She received her Ph.D. degree from University of Roorkee (now IIT Roorkee) in 1980.

Dr. Gupta is currently a professor of chemistry at the Indian Institute of Technology Roorkee (IIT Roorkee). She works is in the field of degradation of persistent organic pollutants, liquid-liquid extraction separation and recovery of metals from wastes. Her work has been published in several international journals of repute including Chemosphere, Journal of Hazardous Materials, Analytica Chimica Acta, Separation Science and Technology, Hydrometallurgy etc.

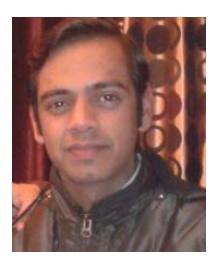

Himanshu Gupta is a doctorate research fellow at the Chemistry Department of Indian Institute of Technology Roorkee (IIT Roorkee) since July, 2010. He acquired his bachelor degree of science from Rohilkhand University in 2008 and master degree of science in organic chemistry from Aligarh Muslim University, India in 2010 .

Mr. Himanshu is currently working in the field of determination, degradation and removal of organic pollutants from different environmental matrices. He plans to continue his work in the field of enviroanalytical chemistry after his doctorate. 